\title{
A woman with anemia and a small-bowel obstruction
}

A previously well 60-year-old A woman presented to hospital with a 3-week history of fatigue, anorexia, abdominal pain, nausea and vomiting, and a 4-kg weight loss. She had previously consulted her general practitioner about an episode of diarrhea and dark stools and was found at that time to have anemia (hemoglobin level $67 \mathrm{~g} / \mathrm{L}$, mean corpuscular volume $65.1 \mathrm{fL}$ ) with mild leukocytosis (leukocyte count $16.6 \times 10^{\circ} / \mathrm{L}$, neutrophil count $\left.13.2 \times 10^{\%} / \mathrm{L}\right)$ and thrombocytosis (platelet count $975 \times 10^{9} / \mathrm{L}$ ). Her history included postpolio syndrome, retinitis pigmentosa, benign nontoxic goiter (for which she was taking thyroxine as suppressive therapy) and, 11 years before admission, excision of a nodular melanoma of the skin (Clark level $\mathrm{V}$ : penetration through the dermis to the subcutaneous fat).

On examination the woman was found to have a firm, irregular, mobile mass about the size of a tennis ball in her left lower quadrant and tenderness, but no rebound or guarding. Her bowel sounds were hyperactive. The woman was admitted to hospital for bowel rest, intravenous fluids and investigation of her anemia.

Three separate stool specimens were positive for occult blood. Colonoscopy revealed uncomplicated diverticulosis, and results of upper endoscopy and mucosal biopsies were unremarkable. A small-bowel followthrough series showed a mass lesion in the lower left quadrant, with a dilated proximal jejunal loop (Fig. 1). At open laparotomy, a single, large, 9-cm intramural nodule with an ulcerated mucosa was found in the patient's jejunum. The mass was resected and identified histolog\pm ically and immunochemically to $\overrightarrow{2}$ be a melanoma metastatic to the small intestine. Postoperatively, the woman's gastrointestinal symptoms resolved, and she was discharged home. Despite 2 small lung nodules identified on a subsequent high-resolution

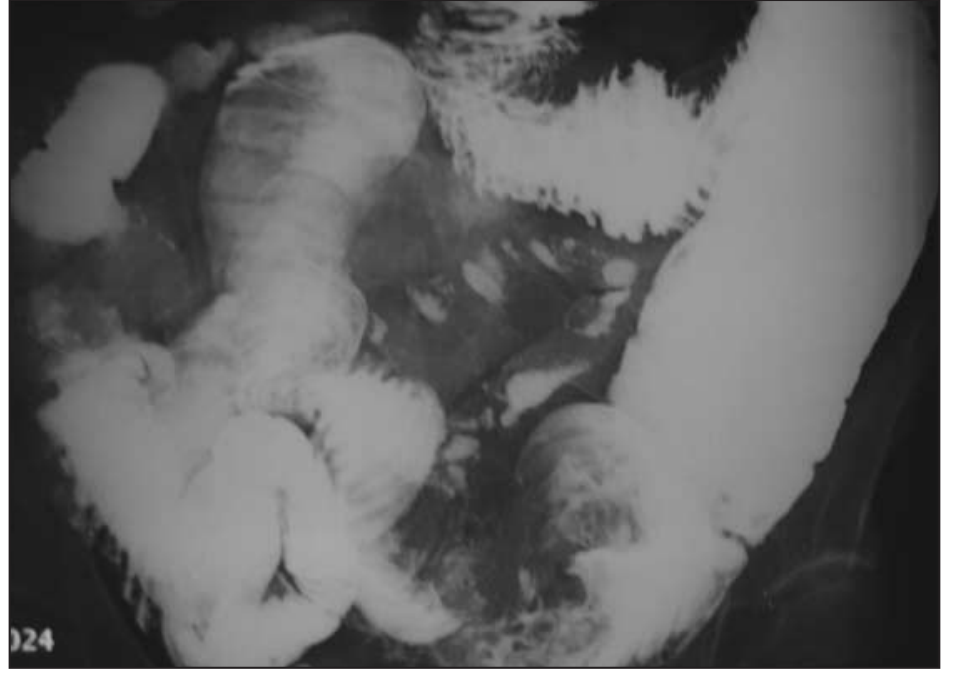

CT scan of the chest, the patient remained well 8 months after being admitted. She declined interferon- $\alpha$ treatment.

Melanoma is the most common tumour to metastasize to the gastrointestinal tract, in particular the small intestine, where it can simulate acute appendicitis and cause gastrointestinal bleeding or obstruction. ${ }^{1}$ Although $4 \%$ of patients with melanoma are found to have clinically significant metastases to the small intestine, many more such metastases are identified at autopsy. ${ }^{2}$ A recent case series included 32 melanoma patients with confirmed metastasis to the small intestine. ${ }^{3}$ The most common presenting symptom was abdominal pain (60\% of patients); other symptoms included bowel obstruction (47\%), nausea and vomiting (41\%) and gastrointestinal bleeding $(30 \%)$. An abdominal mass was identified at presentation in only $10 \%$ of patients. ${ }^{3}$ Given the relatively low sensitivity of imaging studies (from $58 \%$ for smallbowel follow-through exams to $66 \%$ for contrast-enhanced CT scans), ${ }^{3}$ patients with a history of melanoma who have unexplained abdominal pain or anemia, or both, often undergo exploratory surgery to rule out gastrointestinal metastases. About 50\% with gastrointestinal metastases have 3 or fewer lesions. ${ }^{3}$ Although the textbook description of the gross appearance of these lesions is one of a discrete polypoid mass with a central ulceration (a "bull's eye" sign), ${ }^{4}$ such an appearance is uncommon. In the absence of other obvious distant metastases, tumours are often resected surgically. Resection allows a definitive diagnosis and, although a cure is rare, can prolong overall and symptom-free survival. ${ }^{5}$

\section{Mario Pirisi}

Monica Leutner

Sandra Grazioli

Ettore G. Bartoli

Department of Medical Sciences

University of East Piedmont

Novara, Italy

\section{References}

1. Wilson BG, Anderson JR. Malignant melanoma involving the small bowel. Postgrad Med f 1986;62:355-7.

2. Reintgen DS, Thompson W, Garbutt J, Seigler HF. Radiologic, endoscopic and surgical considerations of malignant melanoma metastatic to the small intestine. Curr Surg 1984:41(2):87-9.

3. Bender GN, Maglinte DD, McLarney JH, Rex D, Kelvin FM. Malignant melanoma: patterns of metastasis to the small bowel, reliability of imaging studies, and clinical relevance. $\mathrm{Am}$ 7 Gastroenterol 2001;96(8):2392-400.

4. Eisenberg RL, editor. Bulls-eye lesion in the gastrointestinal tract. Gastrointestinal radiology: a pattern approach. 2nd ed. Philadelphia: JB Lippincott; 1990. p. 865-70.

5. Agrawal S, Yao TJ, Coit DG. Surgery for melanoma metastatic to the gastrointestinal tract. Ann Surg Oncol 1999;6(4):336-44. 